\title{
Bafilomycin A1 inhibits autophagy and induces apoptosis in MG63 osteosarcoma cells
}

\author{
ZONGGANG XIE*, YE XIE* , YOUJIA XU, HAIBIN ZHOU, WEI XU and QIRONG DONG \\ Department of Orthopedics, The Second Affiliated Hospital of Soochow University, Suzhou, Jiangsu 215004, P.R. China
}

Received May 24, 2013; Accepted April 3, 2014

DOI: $10.3892 / \mathrm{mmr} .2014 .2281$

\begin{abstract}
The purpose of the present study was to investigate the effects of bafilomycin A1 (BafA1) on proliferation, apoptosis and autophagy in MG63 osteosarcoma cells. The growth rate of MG63 cells was determined using a Cell Counting Kit-8 assay. The mitochondrial membrane potential $(\Delta \psi)$ was measured using a fluorescent probe, JC-1, and the inhibition of autophagy and apoptosis was monitored by transmission electron microscopy. In addition, the inhibition of autophagy was monitored by western blot analysis of microtubule-associated protein 1 light chain 3 (LC3), and the ratio of LC3-II/LC3-I protein levels was calculated as an indicator of the extent of autophagy. Furthermore, the expression levels of specific proteins associated with autophagy, including p53, Beclin1 and p62, were detected in cultured MG63 cells by western blotting. It was shown that the viability of MG63 cells was inhibited following the use of BafA1, and an induction in the expression levels of the apoptosis-related protein p53 and the autophagic protein Beclin1 was detected. Furthermore, a collapse in $\Delta \psi$ was observed, together with an induction of apoptotic cell death, following treatment with BafA1. Therefore, following BafA1-mediated inhibition of autophagy, the inhibition of MG63 cell proliferation and induction of apoptosis were observed.
\end{abstract}

\section{Introduction}

Osteosarcoma is one of the most common malignant tumors of the musculoskeletal system $(1,2)$ with a survival rate of $<20 \%$ when solely treated by surgical intervention (3). Combinatory therapeutic approaches, such as surgery together with systemic chemotherapy, are therefore required for the effective treatment of this cancer $(1,4)$. Previous research $(5)$ has

Correspondence to: Dr Qirong Dong, Department of Orthopedics, The Second Affiliated Hospital of Soochow University, 1055 Sanxiang Street, Suzhou, Jiangsu 215004, P.R. China

E-mail: dqr@szgk.net

*Contributed equally

Key words: MG63, bafilomycin A1, apoptosis, autophagy shown that osteoclasts can be used as a potential therapeutic target in osteosarcoma, due to their prominence within the tumor and their critical function in bone resorption at sites of microfracture or bone destruction. Osteosarcoma cells originate from cells of an osteoblastic lineage, which is characterized by cell secretion of receptor activator of nuclear factor- $\kappa \mathrm{B}$ ligand, a surface bound molecule that induces osteoclast activation. Osteosarcoma may therefore be a suitable candidate for osteoclast-targeted therapy, with osteosarcoma cells being used as a cellular model in which novel therapeutic methods and molecular mechanisms may be researched (5).

Autophagy is central to the pathogenesis of numerous conditions, including aging, cancer, myopathies, neuronal degeneration and microbial infection $(6,7)$. Therefore, an increasing number of novel therapeutic strategies for osteosarcoma are focusing on the modulation of dysregulated autophagy $(8,9)$.

Bafilomycin A1 (BafA1), a macrolide antibiotic, is a known inhibitor of the latter stages of autophagy, inhibiting fusion between autophagosomes and lysosomes by inhibiting vacuolar $\mathrm{H}^{+}$ATPase (10). This has been demonstrated to result in a marked accumulation of autophagosomes, concomitant with apoptotic cell death $(11,12)$.

Since the discovery of BafA1 and the identification of its molecular effects in vitro on autophagy-mediated cell death, BafA1 may be considered to be a central modulator of both apoptosis and autophagy. The present study aimed to detect the effects of BafA1 on cell growth and apoptosis in MG63 cells in vitro.

\section{Materials and methods}

Reagents. The MG63 osteosarcoma cell line was purchased from the Shanghai Institute of Cell Biology, Chinese Academy of Sciences (Shanghai, China). RPMI-1640 medium was purchased from Gibco-BRL (Rockville, MD, USA); BafA1 was purchased from Biovision (Shanghai, China); L-glutamine was obtained from Sigma (St. Louis, MO, USA); and antibodies against p53, p62, Beclin1 and microtubule-associated protein 1 light chain 3 (LC3) were purchased from Cell Signaling Technology, Inc. (Beverly, MA, USA).

Drug preparation. BafA1 was diluted in dimethylsulfoxide (DMSO) to a final working concentration of $1 \mu \mathrm{mol} / 1$ and DMSO was used as the vehicle control. 
Cell culture and viability assay. MG63 cells were cultured in RPMI-1640 with $10 \%$ fetal bovine serum and $4 \mathrm{mmol} / \mathrm{l}$ L-glutamine. For all assays, the cells were cultured at $37^{\circ} \mathrm{C}$ in humidified incubators with $5 \% \mathrm{CO}_{2}$ and $95 \%$ air. The cell viability was assessed using the Cell Counting Kit-8 (CCK-8; Dojindo Labotatories, Kumamoto, Japan) assay. Cells were plated in 96-well plates at a density of $7 \times 10^{4}$ cells/well and treated with BafA1 for 6,12 or $24 \mathrm{~h}$. Cell viability was subsequently assessed by the addition of $10 \mu$ l CCK- 8 solution to each well, $24 \mathrm{~h}$ after BafA1 treatment. Following incubation with CCK- 8 for $4 \mathrm{~h}$, the optical absorbance at $570 \mathrm{~nm}$ was measured. Each experiment was performed in triplicate (13).

Detection of mitochondrial potential $(\Delta \Psi)$. The $\Delta \Psi$ was determined using the KeyGEN Mitochondrial Membrane Sensor kit (KeyGEN, Nanjing, China) according to the manufacturer's instructions. Cells were first treated with BafA1, harvested and then washed three times with $5 \mathrm{ml}$ phosphate-buffered saline (PBS), prior to centrifugation and aspiration. The cells were then re-suspended in $0.5 \mathrm{ml}$ diluted MitoSensor reagent $(1 \mu \mathrm{mol} / \mathrm{m} 1$ in incubation buffer; Becton-Dickinson, Heidelberg, Germany). Following incubation with the fluorescent probe JC-1 for 20-30 min, the cells were washed in $0.2 \mathrm{ml}$ incubation buffer and resuspended in $40 \mu \mathrm{l}$ incubation buffer, prior to re-washing and re-suspension in $1 \mathrm{ml}$ PBS. The cells were then analyzed by flow cytometry (FACScan; Becton-Dickinson).

Detection of apoptosis. Cells treated with BafA1 for 6-24 h were harvested and washed three times with $5 \mathrm{ml} \mathrm{PBS} / 0.1 \%$ fetal calf serum wash buffer, centrifuged and aspirated. The cells were then re-suspended in wash buffer containing $20 \mu \mathrm{g} / \mathrm{ml}$ propidium iodide (PI), $500 \mu \mathrm{g} / \mathrm{ml}$ RNase and $0.03 \%$ Nonidet P-40 and subsequently analyzed by flow cytometry. The percentage of apoptotic cells was taken as the percentage of cells with a lower DNA content than that of cells in the $\mathrm{G}_{0}-\mathrm{G}_{1}$ phase in the PI intensity-area histogram plot (14).

Total cell protein extraction and western blotting. Cells were cultured for 24-48 $\mathrm{h}$ prior to lysis in buffer containing $50 \mathrm{mmol} / \mathrm{l}$ Tris- $\mathrm{HCl}$ (pH 8.0), $150 \mathrm{mmol} / \mathrm{l} \mathrm{NaCl}, 1 \%$ (v/v) Triton X-100 and a protease inhibitor cocktail (1:100 dilution; Sigma, Shanghai, China). The protein concentration was determined using Bradford reagent. The proteins were then separated by electrophoresis using $8.5 \%$ polyacrylamide gels and transferred onto nitrocellulose membranes. The membranes were subsequently exposed to anti-Beclin 1 (1:1,000), -p53 (1:2,000), -p62 (1:1,000) and -LC3 (1:1,000) antibodies and incubated at $4{ }^{\circ} \mathrm{C}$ overnight, prior to exposure to horseradish peroxidase-conjugated secondary antibody $(1: 3,000)$ for $1 \mathrm{~h}$ at room temperature. $\beta$-actin $(1: 5,000 ;$ Sigma $)$ was used as a loading control. Membranes were developed using an enhanced chemiluminescence detection system (Denville Scientific, Inc., Plainfield, NJ, USA) and exposed to $\mathrm{X}$-ray films (15).

Transmission electron microscopy. Following treatment with BafA1, the cells were fixed in ice-cold $2.5 \%$ glutaraldehyde in $0.1 \mathrm{M}$ PBS and stored at $4^{\circ} \mathrm{C}$, prior to further processing. The cells were post-fixed in $1 \%$ osmium tetroxide in ice-cold

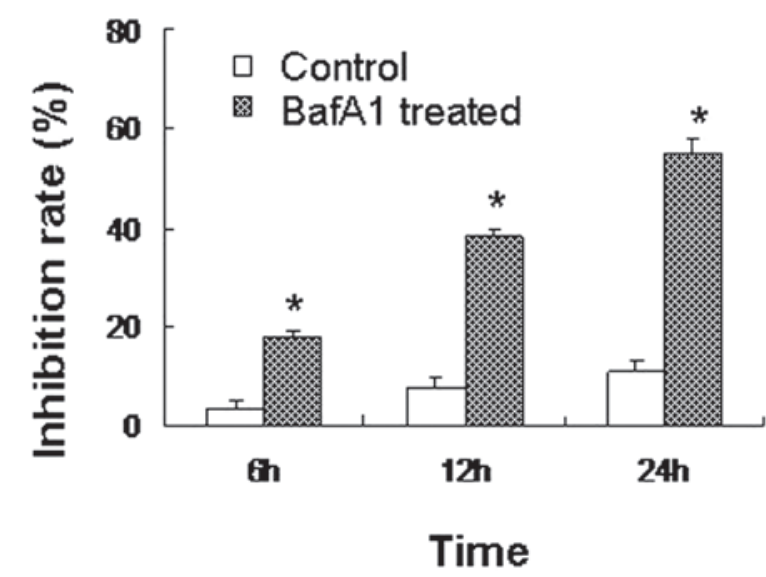

Figure 1. Reduced viability of MG63 cells following BafA1 treatment. MG63 cells $\left(7 \times 10^{4}\right.$ cells $\left./ \mathrm{ml}\right)$ were cultured with BafA1 $(1 \mu \mathrm{mol} / 1)$ for 6,12 and $24 \mathrm{~h}$ and cell viability was analyzed by Cell Counting Kit- 8 assay. Values are presented as the mean \pm standard deviation of three independent experiments. ${ }^{*} \mathrm{P}<0.05$ as compared with the control group. BafA1, bafilomycin A1.

$2.5 \%$ glutaraldehyde in $0.1 \mathrm{M}$ PBS and then dehydrated through an alcohol series prior to embedding in $\mathrm{Epon}^{\mathrm{TM}} 812$ (Electron Microscopy Sciences, Hatfield, PA, USA). The cells were next sectioned using an ultramicrotome (Leica, Wetzlar, Germany). Finally, the sections $(500 \mathrm{~nm})$ were stained with uranyl acetate and lead citrate and examined by transmission electron microscopy (Philips CM120; Philips, Eindhoven, The Netherlands).

Statistical analysis. The data are presented as the mean \pm standard deviation. A Student's t test was used for statistical analysis and a P-value of $<0.05$ was considered to indicate a statistically significant difference.

\section{Results}

BafAl inhibits MG63 cell viability. The CCK-8 assay revealed that the inhibition rate of MG63 cells treated with BafA1 $(1 \mu \mathrm{mol} / \mathrm{l})$ was significantly higher than that of the controls (only vehicle used) $(\mathrm{P}<0.05)$. BafA1 inhibited the proliferation of the MG63 cells, with the rate of inhibition reaching $18 \pm 0.57 \%$ after $6 \mathrm{~h}$ of incubation. The inhibition rate increased to $39 \pm 2.82$ and $56 \pm 3.91 \%$ by 12 and $24 \mathrm{~h}$, respectively (Fig. 1 ).

BafAl induces mitochondrial dysfunction. MG63 cells showed a collapse in the $\Delta \psi$ after $6 \mathrm{~h}$ of exposure to BafA1 $(1 \mu \mathrm{mol} / \mathrm{l})$, with a maximum being reached by $24 \mathrm{~h}$ (Fig. 2). These data therefore indicated that BafA1 could induce mitochondrial dysfunction and apoptosis in MG63 cells.

BafA1 induces apoptosis in MG63 cells. The rate of apoptosis in MG63 cells was assessed by flow cytometry at 6,12 and $24 \mathrm{~h}$ after exposure to BafA1 (1 $\mu \mathrm{mol} / \mathrm{l})$. BafA1-induced cellular apoptosis was evident after 6,12 and $24 \mathrm{~h}$ of treatment (Fig. 3).

BafA1 increases Beclin 1 and p53 protein expression levels in MG63 cells. Western blot analysis was used to assess the effect of BafA1 on the expression of the apoptosis-related proteins 


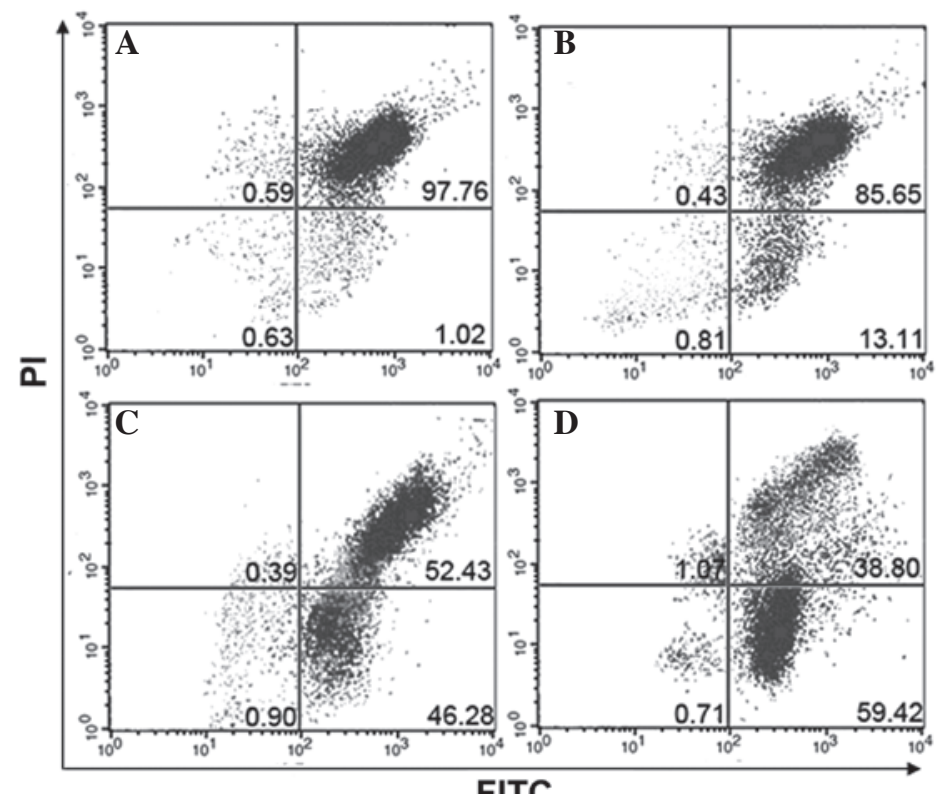

FITC

Figure 2. Flow cytometric analysis of mitochondrial membrane potential in the control and BafA1-treated MG63 cells. The cells were treated with $1 \mu$ mol/1 BafA1 for 6, 12 and $24 \mathrm{~h}$ and were stained with $5 \mu \mathrm{mol} / 1 \mathrm{JC}-1$ for $30 \mathrm{~min}$. (A) Control; (B) 6, (C) 12 and (D) $24 \mathrm{~h}$ after BafA1 treatment. (N=3). PI, propidium iodide; FITC, fluorescein isothiocyanate; BafA1, bafilomycin A1.

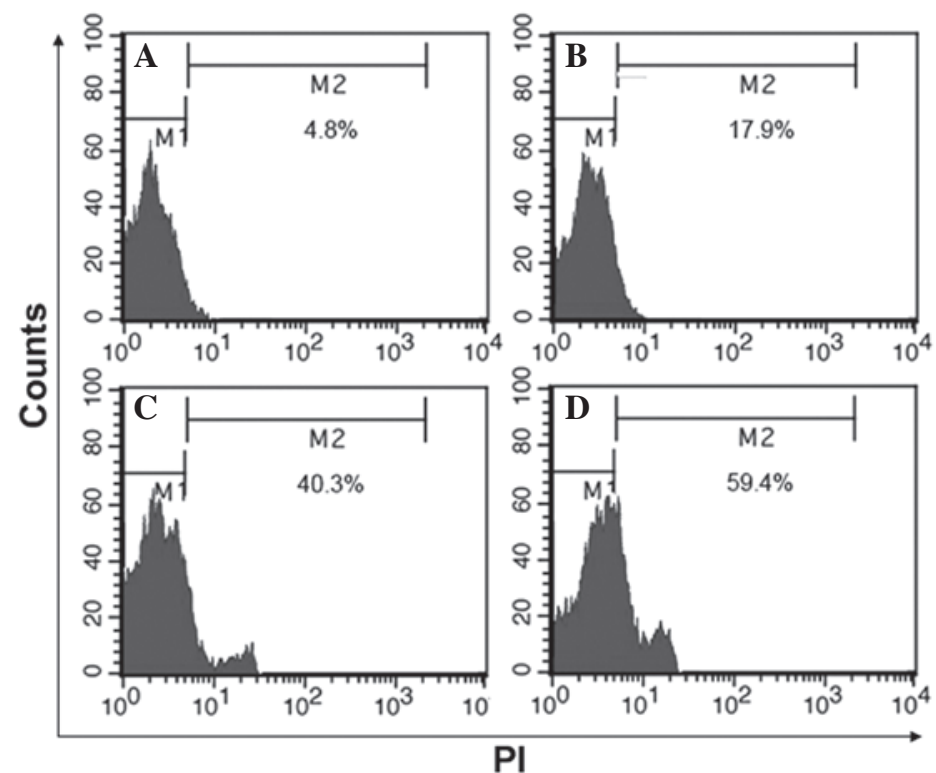

Figure 3. Induction of apoptosis following BafA1 treatment. The MG63 cells were incubated with $1 \mu \mathrm{mol} / 1 \mathrm{BafA} 1$ for the indicated time periods. (A) Control; (B) 6, (C) 12 and (D) $24 \mathrm{~h}$ after BafA1 treatment. (N=3). PI, propidium iodide. BafA1, bafilomycin A1.

Beclin 1 and p53. The results showed that the basal level of p53 protein in the untreated MG63 cells was low. Following incubation with BafA1 $(1 \mu \mathrm{mol} / \mathrm{l})$, the protein expression level of p53 and Beclin 1 was significantly increased 6-24 h after exposure (Fig. 4).

BafA1 downregulates the expression of p62 and LC3-I. Western blot analysis was used to assay whether BafA1 (1 $\mu \mathrm{mol} / \mathrm{l})$ affected the expression of the autophagy-related proteins LC3-I, LC3-II and p62. The results showed that, prior to exposure of MG63 cells to BafA1, the basal levels of p62 and LC3 protein in MG63 cells were high. Following incubation for 6-24 h with BafA1 ( $1 \mu \mathrm{mol} / \mathrm{l})$, the expression levels of p62 and LC3-I were significantly decreased, whereas the protein levels of LC3-II were increased (Fig. 5).

Autophagic activation of lysosomes and impairment of mitochondria with BafAl treatment. As shown in Fig. 6, transmission electron microscopy was used to identify the ultrastructural changes in MG63 cells following BafA1 ( $1 \mu \mathrm{mol} / \mathrm{l})$ treatment. The control cells showed a round shape and the organelles, nuclei and chromatin had a normal appearance (Fig. 6A). By contrast, the BafA1-treated cells exhibited typical signs of apoptosis (Fig. 6B-D). The mitochondria exhibited vacuolization and 


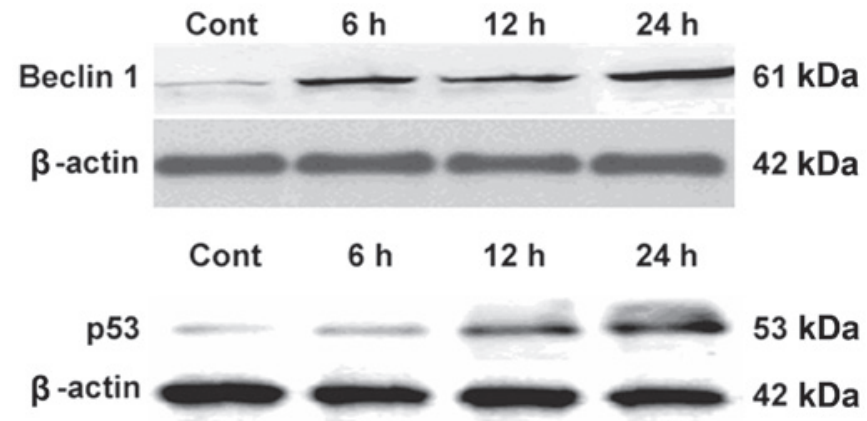

Figure 4. Effects of BafA1 on Beclin 1 and p53 protein expression in MG63 cells. MG63 cells were treated with BafA1 $(1 \mu \mathrm{mol} / \mathrm{l})$ for $6-24 \mathrm{~h}$ then harvested for extraction of total proteins. BafA1 was observed to upregulate the expression of Beclin 1 and p53. kDa, kilodaltons; Cont, control; BafA1, bafilomycin A1.

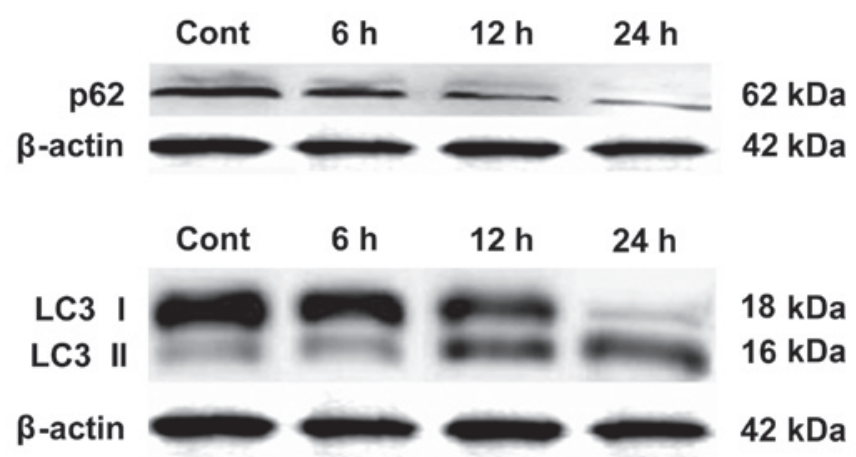

Figure 5. Effects of BafA1 on LC3 and p62 protein expression in MG63 cells. MG63 cells were treated with BafA1 $(1 \mu \mathrm{mol} / \mathrm{l})$ for 6-24 h then harvested for extraction of total proteins. BafA1 downregulated the expression of LC3 and p62 protein. LC3, microtubule-associated protein 1 light chain 3; kDa, kilodaltons; Cont, control; BafA1, bafilomycin A1.

swelling with a complete loss of cristae (Fig. 6C). Numerous isolated membranes, likely deriving from ribosome-free endoplasmic reticulum, were observed. These isolated membranes were elongated and curved, engulfing the cytoplasmic fraction and organelles (Fig. 6C). Prolongation of BafA1 treatment $(1 \mu \mathrm{mol} / \mathrm{l})$ resulted in apoptosis, as well as the loss of organelles and cytoplasm vacuolization (Fig. 6C and D).

\section{Discussion}

BafA1 was shown in vitro to significantly induce $\Delta \psi$ collapse. It has been reported that the mitochondrial permeability transition represents an important cellular event, initiating apoptotic cell death (16). These observations were confirmed by flow cytometry. Taken together, these data indicate that BafA1 can trigger apoptosis in MG63 cells.

Western blot analysis was used to elucidate the possible mechanisms underlying BafA1-mediated apoptosis. It was observed that p53 protein expression levels were increased following BafA1 treatment in MG63 cells. In addition, levels of other indicators of autophagy, including LC3-II and Beclin1, were increased, whereas those of p62 were decreased, similar to the results of Paglin et al (17). Due to the toxic cellular stress imposed by ectopic BafA1 application, p53 was observed to become activated; activated p53 may be hypothesized to
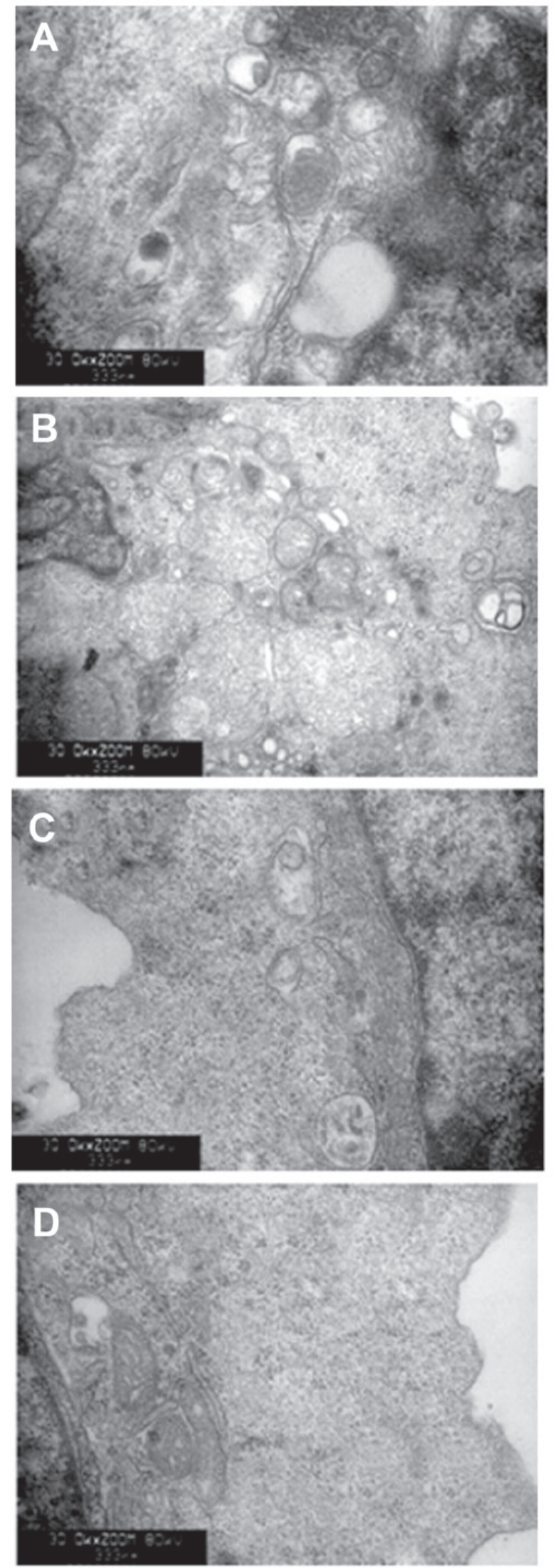

Figure 6. Ultrastructure of MG63 cells undergoing autophagy, apoptosis and necrosis following BafA1 treatment. (A) Untreated MG63 control cells; (B-D) cells treated with BafA1 for (B) 6, (C) 12 and (D) $24 \mathrm{~h}$. Magnification, x10,000. BafA1, bafilomycin A1. 
subsequently act as a transcription factor to regulate downstream genes and promote apoptosis. It is therefore concluded that BafA1 can inhibit autophagy and enhance p53 expression in MG63 cells, resulting in the promotion of MG63 cell apoptosis.

In summary, the present study revealed a new mechanism associated with autophagy inhibition-induced impairment of cell proliferation and induction of cell death of cancer cells. Further investigation of the association between autophagy and apoptosis may unveil novel strategies for tumor therapy.

\section{Acknowledgements}

This study was supported in part by a grant from the National Science Foundation of China (no. 81171730).

\section{References}

1. Raymond AK, Ayala AG and Knuutila S: Conventional osteosarcoma. In: World Health Organization Classification of Tumours. Pathology and Genetics of Tumours of Soft Tissue and Bone. Fletcher CDM, Unni KK and Mertens F (eds). IARC Press, Lyon, pp264-270, 2002.

2. Xiao H, Chen L, Luo G, Son H, Prectoni JH and Zheng W: Effect of the cytokine levels in serum on osteosarcoma. Tumour Biol 35: 1023-1028, 2014.

3. Scully SP, Ghert MA, Zurakowski D, Thompson RC and Gebhardt MC: Pathologic fracture in osteosarcoma : prognostic importance and treatment implications. J Bone Joint Surg Am 84-A: 49-57, 2002.

4. Gelderblom H, Jinks RC, Sydes M, Bramwell VH, van Glabbeke M, Grimer RJ, Hogendoorn PC, McTiernan A, Lewis IJ, Nooij MA, Taminiau AH and Whelan J; European Osteosarcoma Intergroup: Survival after recurrent osteosarcoma: data from 3 European Osteosarcoma Intergroup (EOI) randomized controlled trials. Eur J Cancer 47: 895-902, 2011.
5. Akiyama T, Dass CR and Choong PF: Novel therapeutic strategy for osteosarcoma targeting osteoclast differentiation, bone-resorbing activity, and apoptosis pathway. Mol Cancer Ther 7: 3461-3469, 2008.

6. Malicdan MC, Noguchi S, Nonaka I, Saftig P and Nishino I: Lysosomal myopathies: an excessive build-up in autophagosomes is too much to handle. Neuromuscul Disord 18: 521-529, 2008.

7. Orvedahl A and Levine B: Eating the enemy within: autophagy in infectious diseases. Cell Death Differ 16: 57-69, 2009.

8. Mathew R, Karantza-Wadsworth V and White E: Role of autophagy in cancer. Nat Rev Cancer 7: 961-967, 2007.

9. Carew JS, Nawrocki ST and Cleveland JL: Modulating autophagy for therapeutic benefit. Autophagy 3: 464-467, 2007.

10. Yamamoto A, Tagawa Y, Yoshimori T, Moriyama Y, Masaki R and Tashiro Y: Bafilomycin: A1 prevents maturation of autophagic vacuoles by inhibiting fusion between autophagosomes and lysosomes in rat hepatoma cell line, H-4-II-E cells. Cell Struct Funct 23: 33-42, 1998.

11. Boya P, González-Polo RA, Casares N, et al: Inhibition of macroautophagy triggers apoptosis. Mol Cell Biol 25: 1025-1040, 2005.

12. Shacka JJ, Klocke BJ, Shibata M, Uchiyama Y, Datta G, Schmidt RE and Roth KA: Bafilomycin A1 inhibits chloroquine-induced death of cerebellar granule neurons. Mol Pharmacol 69: 1125-1136, 2006.

13. Qi X, Chen Z, Liu D, Cen J, Gu M. Expression of Dlk1 gene in myelodysplastic syndrome determined by microarray, and its effects on leukemia cells. Int J Mol Med 22: 61-68, 2008

14. Alvarez-Tejado M, Naranjo-Suarez S, Jiménez C, Carrera AC, Landázuri MO and del Peso L: Hypoxia induces the activation of the phosphatidylinositol 3-kinase/Akt cell survival pathway in PC12 cells: protective role in apoptosis. J Biol Chem 276: 22368-22374, 2001.

15. Qi X, Jiang J, Zhu M and Wu Q. Human corin isoforms with different cytoplasmic tails that alter cell surface targeting. J Biol Chem 286: 20963-20969, 2011.

16. Gozuacik D and Kimchi A: Autophagy as a cell death and tumor suppressor mechanism. Oncogene 23: 2891-2906, 2004.

17. Paglin S, Hollister T, Delohery T, et al: A novel response of cancer cells to radiation involves autophagy and formation of acidic vesicles. Cancer Res 61: 439-444, 2001. 